\title{
PENGARUH METODE PENERAPAN MEDIA GRAFIS CHART PIE TERHADAP PRESTASI BELAJAR MATEMATIKA SISWA
}

\author{
Mat Ali \\ ${ }^{a}$ SMP Negeri 1 Sekaran \\ Jln. Melati RT. 01/ RW. 02 Desa Patihan Babat, Lamongan, Jawa Timur matalipaba@gmail.com
}

\begin{abstract}
ABSTRAK
Penelitian ini bertujuan untuk meningkatkan aktifitas siswa dan meningkatkan prestasi siswa dengan menggunakan metode penerapan media grafis chart pie pada pokok bahasan operasi bilangan pecahan. Teknik analisis data menggunakan teknik analisis diskriptif kuantitatif dan kualitatif. Proses penelitian ini di lakukukan dalam dua siklus, masing masing terdiri dari empat tahap : perencanaan, pelaksanaan, observasi, dan refleksi. Subyek penelitian adalah 25 siswa kelas VII B SMP Negeri 1 Sekaran Lamongan tahun pelajaran 2020/2021. Hasil penelitian menunjukkan adanya peningkatan aktifitas siswa dalam kegiatan pembelajaran dan juga menunjukkan peningkatan prestasi siswa.
\end{abstract}

Kata Kunci : Media grafis chart pie, aktifitas siswa, prestasi belajar

\begin{abstract}
This research aims to increase student activities and improve student achievement by using the method of application of graphic media chart pie in fractional numbers operation subject. Data analysis techniques using kuantitative and qualitative analysis techniques. This research process is conducted in two cycles, each consisting of four stages: planning, implementation, observation, and reflection. The subjects of the study were 25 students of grade VII B SMP Negeri 1 Sekaran Lamongan in the 2020/2021 school year. The results showed the increasing of student activities in learning and also showed the increasing of student achievement.
\end{abstract}

Keyword(s): Graphic media pie chart, student activities, learning achievement.

\section{PENDAHULUAN}

Berhasil atau tidaknya suatu pendidikan ini salah satunya tergantung dari bagaimana cara guru mendidik siswanya. Cara mendidik ini tidak hanya tentang apa yang terjadi di dalam ruang kelas saat pembelajaran, namun juga apa yang dilakukan guru sebelum pembelajaran dan pasca pembelajaran. Apa yang dilakukan guru sebelum pembelajaran bisa dimaknai sebagai persiapan guru dalam mengajar, sedangkan apa yang dilakukan setelah pembelajaran dimaknai sebagai evaluasi pembelajaran. Dalam perspektif Islam, guru atau pendidik adalah orang yang bertanggung jawab terhadap perkembangan peserta didik, baik potensi kognitif, afektif maupun psikomotorik sesuai dengan nilai-nilai Islam (Rusmaini, 
2011).

Sesuai dengan Undang-Undang nomor 20 tahun 2003 tentang Sistem Pendidikan Nasional, pendidikan nasional bertujuan untuk berkembangnya potensi peserta didik agar menjadi manusia yang beriman dan bertaqwa kepada Tuhan Yang Maha Esa, berakhlak mulia, sehat, berilmu, cakap, kreatif, mandiri, dan menjadi warga Negara yang demokratis serta bertanggung jawab. Berdasarkan hal ini, tujuan utama sistem pembelajaran adalah keberhasilan siswa mencapai tujuan itu (Sanjaya, 2013).

Meningkatkan mutu dan kualitas pendidikan peserta didik salah satunya dengan memperhatikan hasil belajar yang dicapainya. Hasil belajar adalah tingkat keberhasilan yang dicapai oleh siswa setelah mengikuti proses belajar mengajar, dimana tingkat keberhasilan tersebut ditandai dengan skala nilai yang berupa angka, kata ataupun simbol. Hasil belajar tampak sebagai hasil dari perubahan tingkah laku siswa, yang bisa diamati serta bisa diukur dalam bentuk pengetahuan, keterampilan, maupun sikap siswa itu sendiri (Ismail, 2014).

Dalam pendidikan, peranan teknologi telah menjadi hal yang tidak bisa dielakan. Penemuan hardware dan software hendaknya bisa dimanfaatkan dalam peningkatan mutu dan kualitas pendidikan salah satunya pembuatan media yang interaktif. Media merupakan segala bentuk benda yang digunakan untuk proses penyaluran informasi (Sanjaya, 2012). Adapun macam-macam media antara lain yaitu, media audio, media visual, media audio visual, media grafis dan lain-lain.

Banyak penelitian yang menunjukkan efektivitas penggunaan media untuk meningkatkan hasil belajar siswa. Diantaranya menggunakan alat peraga (Nugroho \& Shodikin, 2018; Rahayu, dkk., 2017), media animasi (Shodikin, 2017; Novianti \& Shodikin, 2018), media grafis (Aardini, 2013; Antani, dkk., 2016; Febrianti, 2019; Hernaeny \& Azhari, 2017; Hidayat, dkk., 2014; Kasmiatun, 2016; Lestari, dkk., 2019; Piyanti \& Tastin, 2015; Safei, 2007; Suryanti, 2020), serta media online (Sumarno, dkk., 2017; Fauzan \& Shodikin, 2012). Penerapan media salah satunya diharapkan menjadikan belajar lebih aktif. Agar belajar menjadi aktif siswa harus menggunakan otak, mengkaji gagasan, memecahkan masalah, dan menerapkan apa yang mereka pelajari. Belajar aktif menuntut harus gesit, menyenangkan, bersemangat dan penuh gairah. Siswa bahkan sering meninggalkan tempat duduk mereka, bergerak leluasa dan berfikir keras (Melvin, 2004).

Penggunaan media grafis chart pie yang diaplikasikan di program 
animasi slide powerpoint adalah salah satu upaya pembelajaran dengan menerapkan perkembangan teknologi saat ini. Media slide powerpoint merupakan media perangkat lunak pengelola presentasi, objek, teks, grafik, video, suara, dan objek-objek lainnya yang dimasukkan dalam beberapa halaman yang efektif, profesional, dan juga mudah (Elcom, 2010). Tentunya diharapkan terjadi pembelajaran yang menantang, menarik dan menyenangkan sehingga tujuan pembelajaran yang diharapkan dapat mudah tercapai. Selain tujuan tersebut, pembelajaran ini diharapkan akan meningkatkan hasil belajar siswa. Oleh karena itu, tujuan penelitian ini adalah untuk melihat pengaruh metode penggunaan media grafis chart pie terhadap aktivitas dan prestasi belajar matematika.

\section{METODE PENELITIAN}

Penelitian ini termasuk jenis penelitian tindakan kelas dan rancangan penelitian ini sesuai dengan Kemmis dan Mc. Taggart (dalam Arikunto, 2006) yang terdiri dari 4 tahap yaitu perencanaan, pelaksanaan, observasi, dan refleksi.

Dalam hal ini peneliti bertindak sebagai guru. Adapun kegiatan belajar mengajar menggunakann metode penerapan media grafis chart pie dan mengacu pada rencana perbaikan pembelajaran dengan memperhatikan revisi pada siklus sebelumnya. Subyek penelitian adalah siswa Kelas VII-B SMP Negeri 1 Sekaran Kecamatan Sekaran semester ganjil tahun pelajaran 2020/2021 sebanyak 25 siswa. Siklus penelitian ini dilaksanakan dalam dua siklus. Siklus 1 dilaksanakan tanggal 14 September 2020 dan siklus 2 dilaksanakan tanggal 21 September 2020. Pada setiap siklusnya dilaksanaan dengan alokasi waktu 90 menit

Adapun dalam tahap pengumpulan data ini, peneliti menggunakan data dari angket tertutup karena jawaban sudah disediakan dan lembar observasi yang diisi oleh temuan pada saat pembelajaran berlangsung. Selain itu juga digunakan hasil tes formatif siswa dari setiap akhir pembelajaran per siklus dengan tujuan untuk mengetahui tingkat keberhasilan siswa dalam kegiatan belajar mengajar yang telah dilakukan.

Indikator keberhasilan tindakan pada penelitian ini dikatakan berhasil jika terdapat kenakian dari hasil observasinya dan kenaikan dari hasil formatifnya dari siklus 1 ke siklus 2 .

\section{HASIL DAN PEMBAHASAN}

Pada tahap pelaksanaan tindakan penelitian ini didasari data awal sebelum dilaksanakan proses pembelajaran dengan menggunakan metode penerapan media 
grafis chart pie. Data awal / pra siklus dijadikan acuan atau evaluasi akan keberhasilan kegiatan penelitian ini. Kegiatan pelaksanaan siklus I dan siklus II mengacu pada revisi data sebelumnya.

Adapaun data revisi awal yang didapat sebelum menerapkan metode penerapan media grafis chart pie adalah:

1). Guru perlu menyampaikan tujuan pembelajaran yang dicapai, serta memfokuskan perhatian siswa pada topik yang dibahas.

2). Guru perlu lebih terampil dalam memotivasi siswa, dimana siswa diajak untuk terlibat langsung dalam setiap kegiatan yang akan dilakukan.

3). Guru harus selalu bersemangat dalam memotivasi siswa sehingga siswa bisa lebih antusias.

4). Kurangnya aktifitas siswa dalam kegiatan diskusi kelompok. Dalam hal ini peneliti bertindak sebagai guru sekaligus peneliti, proses pembelajaran mengacu pada rencana perbaikan pembelajaran yang telah dipersiapkan.

Tabel 1. Aktiftas siswa

\begin{tabular}{|c|c|c|c|c|c|}
\hline \multirow[b]{2}{*}{ No. } & \multirow[b]{2}{*}{ Aktivitas yang diamati } & \multirow{2}{*}{$\begin{array}{l}\text { Skor } \\
\text { Mak. }\end{array}$} & \multicolumn{3}{|c|}{ Hasil } \\
\hline & & & $\begin{array}{c}\text { Pra } \\
\text { Siklus }\end{array}$ & Siklus 1 & Siklus 2 \\
\hline 1. & Mengerjakan tugas kelompok secara aktif & 3 & 1 & 2 & 3 \\
\hline 2. & $\begin{array}{l}\text { Berlatih melakukan kerjasama } \\
\text { menyusunn peta konsep (berada dalam } \\
\text { tugas, mengambil giliran, bertanya, } \\
\text { mendengarkan dengan aktif, } \\
\text { memberikan dan menghargai kontribusi) }\end{array}$ & 3 & 1 & 2 & 3 \\
\hline & \multicolumn{5}{|l|}{ Aktif dalam kegiatan diskusi kelas } \\
\hline & $\begin{array}{l}\text { - Seluruh perhatian diarahkan pada } \\
\text { materi pelajaran }\end{array}$ & 3 & 2 & 2 & 2 \\
\hline & $\begin{array}{l}\text { - Mengikuti kegiatan diskusi secara aktif } \\
\text { - Pertanyaan yang diajukan }\end{array}$ & 3 & 2 & 2 & 3 \\
\hline & $\begin{array}{l}\text { relevan dengan tema yang } \\
\text { didiskusikan } \\
\text { - Menjawab pertanyaan sesuai }\end{array}$ & 3 & 2 & 2 & 3 \\
\hline & $\begin{array}{l}\text { dengan maksud dan tujuan } \\
\text { pertanyaan }\end{array}$ & 3 & 1 & 1 & 2 \\
\hline & $\begin{array}{l}\text { - Memberikan pendapat/tanggapan } \\
\text { yang argumentative }\end{array}$ & 3 & 1 & 1 & 2 \\
\hline & $\begin{array}{l}\text { - Menghargai saran dan pendapat } \\
\text { sesama teman }\end{array}$ & 3 & 2 & 3 & 3 \\
\hline & Total & 24 & 11 & 17 & 22 \\
\hline & Ketercapaian (\%) & & $46 \%$ & $71 \%$ & $92 \%$ \\
\hline
\end{tabular}




\section{Aktivitas Siswa}

Hasil aktivitas siswa yang diperoleh dari siswa kelas VII-B SMP Negeri 1 Sekaran tahun pelajaran 2020/2021 pada mata pelajaran Matematika Pokok Bahasan Operasi Bilangan Pecahan dengan metode kelompok biasa atau sebelum dan sesudah diterapkannya metode penerapan media grafis chart pie adalah dapat dilihat pada Tabel 1 berikut.

Dari Tabel 1 dapat dijelaskan bahwa penerapan metode penerapan media grafis chart pie menunjukkan adanya peningkatan aktifitas siswa selama pembelajaran dari sebelum dilakukan penerapan metode penerapan media grafis chart pie (pra siklus $46 \quad \%$ ) setelah menggunakan metode penerapan media grafis chart pie menjadi $71 \%$ siklus I dan $92 \%$ pada siklus II.

\section{Hasil Tes Formatif}

Banyaknya siswa yang tuntas dan tidak tuntas berdasarkan hasil tes formatif pada masing-masing siklus ditunjukkan Gambar 1 berikut.
HASIL TES FORMATIF (JUMLAH SISWA TUNTAS)
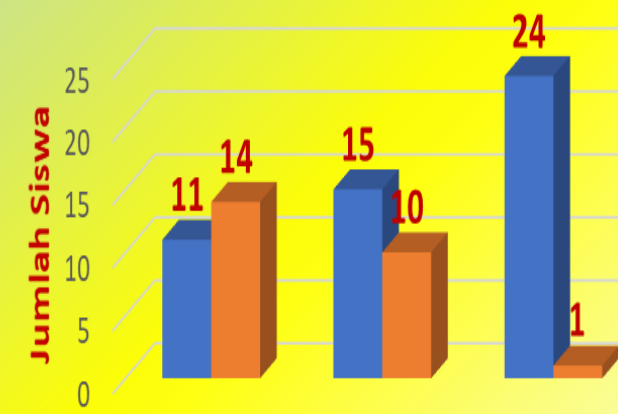

Pra siklus Siklus 1 Siklus 2

\section{Tuntas Belum Tuntas}

Gambar 1. Hasil tes formatif (jumlah siswa yang tuntas dan tidak tuntas)

Selanjutnya, perbandingan nila rata-rata dan presentasi berdasarkan hasil tes formatif ditunjukkan pada Gambar 2.

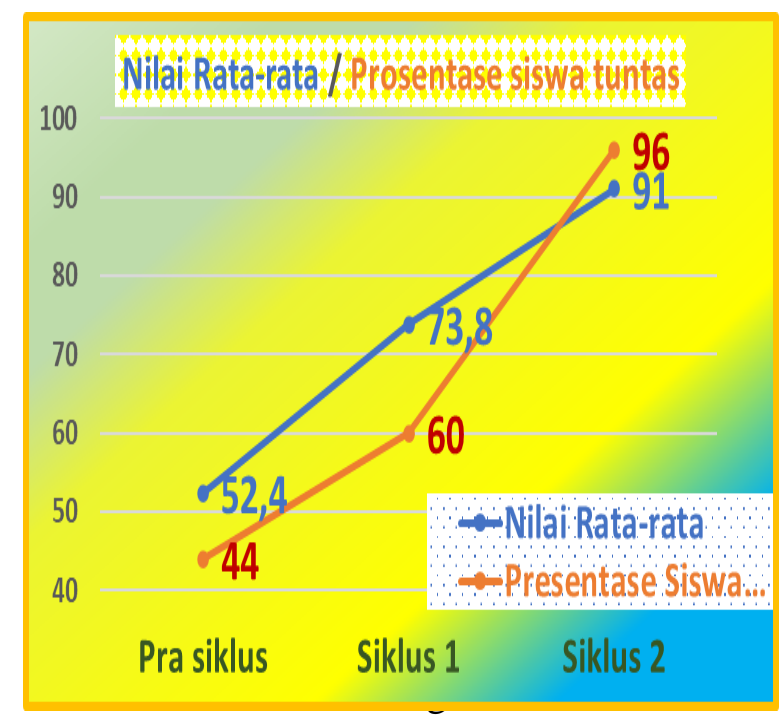

Dari Gambar 1 di atas dapat dijelaskankelas dan presentase ketuntasan bahwa penerapan metode penerapan media grafis chart pie menunjukkan adanya Dari diagram 2 di atas dapat penambahan siswa yang tuntas sekaligusdijelaskan bahwa penerapan metode berkurangnya siswa yang tidak tuntas. penerapan media grafis chart pie menunjukkan adanya:

Peningkatan prestasi siswa selama pembelajaran dari rata rata 52,4 
sebelum di lakukan penerapan metode penerapan media grafis chart pie menjadi rata rata 73,8 setelah menggunakan metode penerapan media grafis chart pie siklus I dan rata rata 91 pada siklus II.

Begitu pula dengan ketuntasannya dari $44 \%$ sebelum di lakukan penerapan metode penerapan media grafis chart pie menjadi $60 \%$ setelah menggunakan metode penerapan media grafis chart pie siklus I dan $96 \%$ pada siklus II.

Secara umum aktifitas siswa dan hasilnya telah terlaksana dengan baik dalam proses pembelajaran dengan penerapan metode penerapan media grafis chart pie. Dari data-data yang telah diperoleh dapat diuraikan bahwa:

1). Selama proses pembelajaran guru telah melaksanakan pembelajaran dengan baik. Meskipun ada aspek yang belum sempurna, tetapi persentase pelaksanaannya untuk masing-masing aspek cukup besar.

2).Berdasarkan data hasil pengamatan diketahui bahwa siswa aktif selama proses belajar mengajar berlangsung.

3).Kekurangan pada siklus sebelumnya sudah mengalami perbaikan dan peningkatan sehingga menjadi lebih baik.

4).Aktifitas siswa mengalami peningkatan terus tiap siklus

5).Hasil belajar siswa mengalami peningkatan terus tiap siklus.

\section{KESIMPULAN DAN SARAN}

Kegiatan pembelajaran yang telah dilaksanakan selama 2 siklus ini dapat meningkatkan prestasi belajar siswa dalam pembelajaran Matematika dan berdasarkan seluruh pembahasan serta analisis dan observasi yang telah dilakukan oleh guru dan teman sejawat dapat disimpulkan sebagai berikut:

Pembelajaran dengan metode penerapan media grafis chart pie memiliki dampak positif dalam meningkatkan aktifitas/ motivasi siswa. Pemahaman siswa terhadap materi melalui keterampilan proses benar-benar mempunyai makna bagi siswa karena siswa mengalami sendiri pembelajaran secara nyata dan ikut secara langsung.

Penerapan metode penerapan media grafis chart pie mempunyai pengaruh positif ditunjang dengan media yang mendukung bagi siswa Kelas VII-B SMP Negeri 1 Sekaran Kecamatan Sekaran Kabupaten Lamongan Tahun Pelajaran 2020/2021 sehingga dapat meningkatkan prestasi belajar siswa dari rata rata 52,4 dan ketuntasan $44 \%$ pada prasiklus dan menjadi 91,0 dan ketuntasan $96 \%$ pada siklus II.

Berdasarkan dari kesimpulan tersebut dapat dikemukakan saran, bahwa metode pembelajaran apapun yang digunakan dalam kegiatan pembelajaran, diharapkan selalu 
memposisikan siswa sebagai pusat perhatian dan perlakuan (subyek didik). Peranan guru dalam pembentukan pola proses pembelajaran di kelas bukan ditentukan oleh metode hal yang digunakan melainkan bagaimana cara menyelesaikan masalah yang ada dalam kelas tersebut dengan memperhatikan peran aktif siswa.

Metode penerapan media grafis chart pie merupakan salah satu alternatife metode pembelajaran kooperatif di sekolah. Untuk pengembangannya di sekolah guru diharapkan dapat menerapkan metode tersebut sesuai dengan kondisi kelasnya masing-masing dan kompleksitas materi yang akan diajarkan.

\section{DAFTAR PUSTAKA}

Aardini, K.A. (2013). Meningkatkan hasil Belajar Matematika Materi Pengolahan Data Menggunakan Media Grafis di Kelas VI SDN Jatiganggong II Jombang. Jurnal Penelitian PGSD UNESA. Vol 1(2), pp. 1-6.

Antani, N.P.J., Wiarta, I. W. Negara, I.G.A. (2016). Implementasi PBL Berbantuan Media Grafis Dapat Meningkatkan Keaktifan Dan Penguasaan Kompetensi Pengetahuan Matematika Siswa SD. Jurnal PGSD UPG Singaraja, Vol. 4(1), pp. 1-11. Arikunto. S, (2006). Prosedur Penelitian
Suatu Pendekatan Praktek. Jakarta: Reinika Cipta.

Elcom, (2010). Belajar Kilat Microsoft Office 2010. Jakarta: Andi Publisher.

Fauzan, A., \& Shodikin, A.(2012). "Sinau Online" E-Learning Dengan Sistem Evaluasi Pembelajaran Multi-User Dilengkapi Deteksi Wajah. Pakar Pendidikan, Vol. 10 (1), pp. 1-9.

Febrianti, F. (2019). Efektifitas penggunaan media grafis dalam meningkatkan motifasi belajar siswa, Prosiding UNSAT Serang, Vol. 2(1) pp. 667-677.

Hernaeny, U. \& Azhari, A.M. (2017). Pengaruh Penggunaan Media Grafis Terhadap Kemampuan Komunikasi Matematika Peserta Didik Kelas VIII SMP Yapida Bogor, Sesiomadika Bogor, pp. 146-153. Hidayat, A.A., Hikmat, A. \& Juariah. (2014). Penerapan Media Gambar Pembelajaran Matematika Sebagai Upaya Meningkatkan Kemampuan Pemahaman Matematika Siswa Pada Materi Pokok Pecahan. Jurnal Analisa UIN Sunan Gunung Djati Bandung, Vol (2). pp. 57-65

Ismail, F. (2014). Evaluasi Pendidikan. Palembang: Tunas Gemilang Press. Kasmiatun. (2016). Pemanfaatan Media Gambar Untuk Meningkatkan Hasil 
Belajar Matematika Siswa Kelas IA, SDN Sidomekar 08 Kec. Semboro Kab. Jember Tahun Pelajarn 20142015. Jurnal Pancaran, Vol 5(2), pp 91-102.

Lestari, S., Handayani, W. \& Sugiman. (2019). Media Gambar Untuk Meningkatkan Daya Tarik siswa kelas 1 SLBN Salatiga dalam Belajar Matematika. Jurnal Prisma, Vol.2, pp. 349-354

Melvin, L. S. (2004). Aktif Learning, 101 Cara Belajar Siswa Aktif. Bandung: Nusa media dan Nuansa.

Novianti, A. \& Shodikin, A. (2018). Pengembangan Bahan Ajar Kalkulus Diferensial Berbasis Animasi dengan Pendekatan Kontekstual dan Kearifan Lokal. De Fermat: Jurnal Pendidikan Matematika, Vol. 1 (2), pp. 12-18.

Nugroho, S., \& Shodikin, A. (2018). Efektivitas Pembelajaran Student Teams Achievement Division (STAD) Berbantuan Komik pada Siswa SD. JMPM: Jurnal Matematika dan Pendidikan Matematika, Vol. 3(1), pp. 22-32.

Piyanti, O. \& Tastin. (2015). Pengaruh Penggunaan Media Grafik Lingkaran Terhadap Hasil Belajar Siswa Pada Mata Pelajaran Matematika Materi Pecahan di Madrasah Ibtidaiyah AlMujtahidin Sumber Harapan Ogan
Komering Ulu Timur. JIP (Jurnal

Ilmiah PGMI) Palembang, Vol 1(1). pp. 8-17.

Rahayu, T. R., Huda, M., \& Shodikin, A. (2017). Pengaruh Model Pembelajaran Kooperatif Tipe TPS dengan Alat Peraga Rubbik terhadap Self Efficacy Siswa pada Materi Kubus dan Balok. Inspiramatika, Vol 3(2), pp. 117123.

Rusmaini. (2011). Ilmu Pendidikan. Palembang: CV. Grafika Telindo Press.

Safei, (2007). Penggunaan media grafis dalam pembelajaran, Jurnal Lentera Pendidikan, Vol. 10(1). pp. 116-123

Sanjaya, W. (2012). Media Komunikasi Pembelajaran. Jakarta: Kencana Prenada Media Group.

Sanjaya, W. (2013). Perencanaan dan Desain Sistem Pembelajaran. Jakarta: Prenata Media Group.

Shodikin, A. (2017). Pengembangan Bahan Ajar Kalkulus Integral Berbasis Animasi. Aksioma: Jurnal Program Studi Pendidikan Matematika, Vol. 6 (1), pp. 1-11.

Sumarno, W.K., Tatik, Shodikin, A. (2017). Developing ConstructivistWebquests Online Materials for TEFL Course. Metathesis: Journal 
of English Language, Literature, and

Teaching, Vol. 1 (2).

Suryanti. (2020). Pengaruh Penggunaan

Media Pembelajaran Powerpoint

Terhadap Hasil Belajar Siswa Kelas

XI SMA. Jurnal Elips Universitas

Pancasakti Makassar, Vol. 1(1), pp.

8-18. 